\title{
EIN NEUER ANFANG?
}




\section{WALTRAUD WENDE - HOHENBERGER}

\section{Ein neuer Anfang?}

Schriftsteller-Reden zwischen 1945 und 1949 


\section{METZLER STUDIENAUSGABE}

CIP-Titelaufnahme der Deutschen Bibliothek

Wende-Hohenberger, Waltraud:

Ein neuer Anfang? : Schriftstellerreden zwischen 1945 und 1949

/ Waltraud Wende-Hohenberger. - Stuttgart : Metzler, 1990

(Metzler Studienausgabe)

ISBN 978-3-476-00725-4

ISBN 978-3-476-03335-2 (eBook)

DOI 10.1007/978-3-476-03335-2

Dieses Werk einschließlich aller seiner Teile ist urheberrechtlich geschützt. Jede Verwertung außerhalb der engen Grenzen des Urheberrechtsgesetzes ist ohne Zustimmung des Verlages unzulässig und strafbar. Das gilt insbesondere für Vervielfältigungen, Übersetzungen, Mikroverfilmungen und die Einspeicherung und Verarbeitung in elektronischen Systemen.

(c) 1990 Springer-Verlag GmbH Deutschland

Ursprünglich erschienen bei J. B. Metzlersche Verlagsbuchhandlung und Carl Ernst Poeschel Verlag GmbH in Stuttgart 1990 


\section{INHALT}

A. EINLEITUNG

I. Relevanz des Themas

II. Erkenntnisinteresse, Fragestellungen und Forschungslage

III. Stoffeingrenzung

B. ERNST WIECHERT - EIN REDNER DER 'ERSTEN STUNDE' 16

I. Voraussetzungen und Rahmenbedingungen der Rede 16

II. Analyse der Rede 19

1. Die Vorgeschichte des 'Dritten Reiches' 19

2. Das 'Schicksal' als zentrale Instanz bei der Entstehung des deutschen Faschismus 21

3. Historische Daten, Fakten und Namen 23

4. Der Widerstand 26

5. Aufgaben der Dichtung 29

6. Das Programm zur Bewältigung von Gegenwart und Zukunft 31

7. Die Jugend als Ansprechpartner 36

8. Aufbau und Rhetorik $\quad 40$

III. Reaktionen auf die Rede 47

1. Rezeption 47

2. Enttäuschung bei Ernst Wiechert 49

C. JOHANNES R. BECHER UND DER 'KULTURBUND ZUR DEMOKRATISCHEN ERNEUERUNG DEUTSCHLANDS'

I. Am Rednerpult 53

II. Vom Expressionisten zum politischen Publizisten $\quad 56$

III. Gründung und Verbot des 'Kulturbundes' 58

IV. Die demokratische Erneuerung als Zukunftsziel 74

1. Antifaschistische Einheitsfront, Demokratiebegriff und Verhältnis zur Sowjetunion $\mathbf{7 4}$

2. Die Frage der Schuld und die Lehren aus der Geschichte 86

3. Literatur und Gesellschaft 97

V. Der Redner Johannes R. Becher 105

VI. Neugründung des deutschen PEN-Clubs 109

D. DER 'ERSTE GESAMTDEUTSCHE SCHRIFTSTELLERKONGRESS' $\begin{array}{ll}\text { NACH DEM ZWEITEN WELTKRIEG } & 115\end{array}$

$\begin{array}{ll}\text { I. Vorgeschichte } & 115\end{array}$

II. Der Kongreß beginnt $\quad 120$

III. Mediale Resonanz 139

E. ALFRED ANDERSCH UND DIE 'GRUPPE 47' 144

I. Ein Vertreter der 'Jungen Generation' 144

1. Begriffsbestimmung 144

2. Leben unter Hitler 145

3. In Gefangenschaft 148

4. Eine eigene Zeitung 150

5. Die Vorgeschichte der 'Gruppe 47' 152

II. Analyse der Rede 156

1. Soziologischer Ansatz versus existentialistische Philosophie Sartrescher Prägung 156

2. Analyse der literarischen Situation 167

2.1. Die innere Emigration 168

2.2. Der offene Widerstand 171

2.3. Der Vorraum der Freiheit 176

3. Aufbau und Stil 180

III. Rezeption der Rede 182 
F. DIE FRANKFURTER JAHRHUNDERTFEIERLICHKEITEN, FRITZ VON UNRUHS 'REDE AN DIE DEUTSCHEN' UND DER 'ZWEITE DEUTSCHE SCHRIFTSTELLERKONGRESS'

I. Historische Rahmenbedingungen

II. Analyse der 'Rede an die Deutschen'

1. Geschichte als persönliches Erleben

2. Rückschau auf die politische Geschichte Deutschlands

3. Die Freiheit des Individuums als entscheidende Kategorie 201

4. Rückblick auf die deutschen Kulturleistungen 203

5. Aufbau und Gliederung 204

6. Ich-Bezug, Schuldfrage und Zukunftsprogramm 208

\begin{tabular}{ll}
7. & Rhetorik und Stil \\
\hline
\end{tabular}

8. Rezeption der Rede 213

III. Schriftsteller treffen sich in der Braubachstraße 216

$\begin{array}{ll}\text { 1. Planungsphase } & 216\end{array}$

$\begin{array}{ll}2 . & \text { Der Kongre } B \text { tagt } \\ & 218\end{array}$

$\begin{array}{ll}3 . & \text { Mediale Berichterstattung } \\ & 238\end{array}$

G. THOMAS MANN IM 'GOETHEJAHR 1949' 242

I. Der Emigrant und sein Vaterland 242

II. Analyse der Rede 255

\begin{tabular}{ll} 
1. Aufbau & 255 \\
\hline
\end{tabular}

2. Biographische und politische Aspekte der Rede 256

2.1. Die politische Entwicklung des Redners 256

$\begin{array}{ll}2.2 \text {. Thomas Mann und die Deutschen } & 261\end{array}$

3. Goethe und die Ambivalenz des 'deutschen Wesens' 264

$\begin{array}{ll}4 . \quad \text { Rhetorik und Stil } & 270 \\ & 273\end{array}$

III. Goethefeiern des Jahres 1949

$\begin{array}{ll}\text { H. SCHLUSSWORT } & 278\end{array}$

$\begin{array}{ll}\text { I. LITERATUR } & 287\end{array}$

J. AUSWAHL-BIBLIOGRAPHIE DER KULTURPOLITISCHEN AN-
SPRACHEN, REDEN UND VORTRÄGE DER JAHRE 1945-1949

$\begin{array}{ll}\text { K. REGISTER } & 329\end{array}$ 